\title{
REFLEXÕES DIDÁTICO-PEDAGÓGICAS SOBRE A “ARTE DE MANDAR" NO ENSINO DE LÍNGUA PORTUGUESA
}

Márcia da Gama Silva Felipe (UERJ)

Resumo: É incontestável a necessidade do ensino das regras gramaticais e da estrutura da Língua Portuguesa. No entanto, não menos necessário é o seu intercâmbio com aspectos culturais que influenciam na prática do falante, principalmente no âmbito do ensino do português como língua estrangeira. $O$ estudo do Modo Imperativo é um exemplo de que essa intercessão se faz necessária, dado que seu aspecto semântico vai muito além das definições normalmente apresentadas em gramáticas tradicionais. A noção de ordem associada a esse modo verbal pode também ser demonstrada em outras construções, raramente contempladas com esse enfoque no ensino hodierno. Isto posto, calcado nos estudos desenvolvidos por Casteleiro (2014), o desenvolvimento deste artigo terá os seguintes objetivos: analisar a realidade do ensino do Modo Imperativo, a partir de pesquisa bibliográfica; refletir acerca de atividades linguísticas, cuja noção de ordem Ihes seja subjacente e propor um tratamento semântico/semiótico para o ensino da noção de ordem e o necessário entrelaçamento Língua e Cultura, cuja negligência coloca em risco todo o esforço em prol do uso proficiente da Língua Portuguesa.

Palavras-chave: Modo Imperativo; Noção de ordem; Semiótica; Cultura.

Abstract: The necessity of teaching grammatical rules and the Portugues Language structure is unquestionable. However, its exchange with cultural aspects that influence the speaker usage, mainly in the portuguese as a foreign language teaching field, is just as necessary. The study of the Imperative Mood is an example that this intercession is necessary, given that its semantic aspect goes way beyond definitions usually presented in traditional grammar. The order idea associated to this verbal mood can also be demonstrated in other structures, rarely contemplated in this current teaching approach. Having said that, based on Casteleiro (2014), the development of this academic paper intends to analyze the reality of the Imperative mood teaching from the bibliographic research; reflect about linguistic activities in which 
the notion of order is underlying and propose a semantic/semiotics approach to the teaching of the order notion and the required weaving of Language and Culture which, if neglected, jeopardizes the whole effort to use the Portugues Language profficiently.

Keywords: Imperative Mood; Notion of order; Semiotics; Culture.

\section{INTRODUÇÃO}

O Modo Imperativo ocupa uma parte muito pequena nas gramáticas tradicionais de Língua Portuguesa. Muitas delas limitam-se a estabelecer o aspecto semântico e a prescrever a formação desse modo verbal, cujo padrão é repetido mecanicamente em manuais e gramáticas normativas. Restrita ao Modo Imperativo, a noção de ordem é minuciosamente estudada por João Malaca Casteleiro (2014) a partir de diversos fatores extralinguísticos que contribuem para expressar essa noção.

Na obra A arte de mandar em português: estudo sintáticoestilístico baseado em autores portugueses e brasileiros (CASTELEIRO, 2014), o pesquisador relaciona elementos determinantes para o entendimento da noção de ordem, como: o ambiente, a intimidade entre os interactantes, o nível de hierarquia - ou sua ausência - e a entonação. Tais circunstâncias estão longe de uma prescrição da língua, pelo contrário, demandam participação ativa do falante na identificação de fatores, a partir dos quais definirá a melhor 
forma de imprimir em sua fala a noção de ordem de que precisa. Dessa forma, dar uma ordem vai além da expressão linguística, apresenta-se como arte: a "arte de mandar", conforme o autor declara no título de sua obra.

Nesse sentido, percebe-se que a influência de aspectos culturais no ato de comunicação configura percalço a ser superado pelo professor. Por isso, entende-se que uma proposta eficaz para o ensino de Língua não deve negligenciar o intercâmbio com a cultura, a fim de que o uso proficiente seja o resultado certo nas aulas de Língua Portuguesa.

A presente pesquisa, de cunho bibliográfico, compõe-se de duas etapas: na primeira, são apresentados os resultados da análise de gramáticas tradicionais e manuais de ensino, estes no âmbito do ensino de Português como Língua Estrangeira (PLE), para que se verifique a forma como o Modo Imperativo, ou noção de ordem, é abordado. Na segunda, calcada em exemplos retirados do livro de Casteleiro (2014), são desenvolvidas algumas análises e propostas para o tratamento do tema.

Esta investigação pretende contribuir para uma análise crítica do ensino de aspectos gramaticais da Língua Portuguesa, seja como língua materna ou segunda língua; com enfoque em aspectos culturais relevantes para o processo ensino-aprendizagem, de forma a promover um ensino de Língua mais produtivo. 


\section{A NOÇÃO DE ORDEM E AS GRAMÁTICAS TRADICIONAIS}

Para que se perceba o estado atual no ensino do Modo Imperativo, foram submetidas à análise cinco gramáticas de autores tradicionais no ensino da Língua Portuguesa e quatro livros direcionados ao ensino da Língua Portuguesa como segunda língua.

\subsection{Gramáticas tradicionais}

A ordem de apresentação dos autores foi estabelecida a partir da abordagem mais tradicional a menos tradicional, a saber: Domingos Paschoal Cegalla (2008), Rocha Lima (2013), Evanildo Bechara (2009), Cunha e Cintra (2008) e Ataliba T. de Castilho (2012).

Duas das obras analisadas, Cegalla e Bechara, apresentam abordagens semelhantes, tanto na definição semântica do Modo Imperativo, quanto na sua formação. Por outro lado, Castilho apresenta uma proposta bastante diferenciada na estruturação da obra. Rocha Lima assume uma visão estritamente normativa.

Domingos Paschoal Cegalla (2008) apresenta um tratamento dos verbos de maneira bem didática e tradicional. Quanto ao Modo Imperativo, não foi detectada nenhuma indicação de tratamento diferenciado. Já o gramático Rocha Lima, apesar da abordagem tradicional no tratamento 
das formas verbais, organiza os tópicos de forma diferente dos outros autores. Essa característica concorre para uma apresentação fragmentada dos modos verbais. O capítulo 10, dedicado ao estudo dos verbos, apresenta uma divisão com foco nos aspectos formais e sintáticos dos verbos. A organização vai desde os verbos regulares e irregulares à conjugação de verbos com os pronomes objetivos diretos $O$, $a$, os, as. A partir desses tópicos, o autor vai demonstrando a conjugação dentro de cada modo.

Por outro lado, Evanildo Bechara apresenta um equilíbrio entre a normatividade e a percepção dos fatos linguísticos. Não passa despercebida a característica que algumas formas verbais apresentam de transmitirem a noção de ordem, em substituição ao Imperativo. No entanto, a análise é diluída no estudo dos modos verbais. Por exemplo, quando fala do Futuro do presente do modo indicativo, esclarece:

o futuro do presente pode ainda exprimir: a) em lugar do presente, incerteza ou ideia aproximada, simples possibilidade ou asseveração modesta: (...) b) em lugar do imperativo, uma ordem ou recomendação, principalmente nas prescrições e recomendações morais (...) (BECHARA, 2009, p.279)

Observa-se, em vários pontos da obra, algumas referências a outros tempos e modos que podem expressar a noção de ordem. $\mathrm{O}$ acadêmico acrescenta que 
os casos aqui lembrados estão longe de enquadrar a trama complexa do emprego de tempos e modos em português. São várias as situações que podem, ferindo os princípios aqui expostos, levar o falante ou escritor a buscar novos meios expressivos. São questões que fogem ao âmbito da Gramática e constituem preocupação da Estilística. (BECHARA, 2009, p.283)

Confirmando essa visão, Bechara (2009, p.619-620) destaca alguns exemplos do que chama "Estilística Morfológica": 1) Plural de convite, 2) Plural de modéstia, 3) O emprego expressivo dos sufixos, 4) O emprego de tempos e modos verbais e 5) Mudanças de tratamento. Os dois últimos itens remetem à influência de João Malaca Casteleiro (2014), nos estudos desses autores.

Cunha e Cintra e Castilho apresentaram uma análise mais profunda no estudo da noção de ordem, aproximando-se da abordagem observada em $A$ arte de mandar em Português (CASTELEIRO, 2014). Vale ressaltar que essa aproximação não é fruto de uma coincidência, uma vez que, nas referências bibliográficas de suas obras, Cunha e Cintra citam João Malaca Casteleiro; Castilho, por sua vez, faz referência a Manuel de Paiva Boléo, este também mencionado por Casteleiro em suas referências bibliográficas.

Ao tratar das formas verbais, Cunha e Cintra (2008) vão deixando pistas de que o Modo Imperativo não é absoluto na 
transmissão da "noção de ordem". No capítulo destinado à Sintaxe dos modos e dos tempos (CUNHA e CINTRA, 2008, p.462481), os autores mencionam, no tópico dedicado aos modos Indicativo $^{1}$ e Subjuntivo ${ }^{2}$, a possibilidade de alguns de seus tempos poderem transmitir um aspecto, até então, específico do Imperativo.

No tópico dedicado ao Futuro do presente, mencionam a possibilidade de esse tempo verbal poder transmitir a noção de ordem: "como expressão de uma súplica, de um desejo, de uma ordem, caso em que o tom de voz pode atenuar ou reforçar o caráter imperativo" (CUNHA e CINTRA, 2008, p.473).

Da mesma forma, o modo Subjuntivo também se apresenta como uma possibilidade de uso para esse fim. No tópico "Subjuntivo Independente" (CUNHA e CINTRA, 2008, p.480481), os autores mencionam que o Subjuntivo "além das noções imperativas" também pode exprimir: desejo, hipótese, concessão, ordem, proibição (essa última na 3ạ pessoa).

O Modo Imperativo tem um capítulo que lhe é dedicado. Nele, Cunha e Cintra, inicialmente, trilham o mesmo caminho de todos os autores, ou seja, tratam da origem desse modo, sua formação e dos aspectos semânticos decorrentes de seu uso.

Embora a palavra imperativo esteja ligada, pela origem, ao latim imperare, "comandar", não é para ordem ou comando que, na maioria dos casos, nos servimos desse

1 Presente p.464; Futuro do presente p.473;

2 Página 481. 
modo. Há, como veremos, outros meios mais eficazes para expressarmos tal noção. Quando empregamos o Imperativo, em geral, temos o intuito de exortar o nosso interlocutor a cumprir a ação indicada pelo verbo. É pois, mais o modo da exortação, do convite, do que propriamente do comando, da ordem (CUNHA e CINTRA, 2008, p.491).

Entretanto, logo a seguir, encontra-se um capítulo destinado aos "Substitutos do imperativo". Nesse tópico, encontram-se: a) Frases nominais, b) Alguns tempos do Modo Indicativo, o Imperfeito do Subjuntivo, c) As formas nominais (infinitivo e gerúndio).

Todas essas possibilidades de expressão, assim como a ideia de reforço ou de atenuação da ordem, seguem de perto o estudo desenvolvido por Casteleiro (2014), que não é de se estranhar, consta nas referências bibliográficas da obra de Cunha e Cintra.

Não distante dessa realidade, Castilho apresenta um tratamento diferenciado, visto que não se limita a demonstrar as variadas formas possíveis para a comunicação da ordem. O assunto é introduzido com um tratamento histórico e semântico do tema. Considera a etimologia do Imperativo e ressalta o abandono da história pelas gramáticas escolares para privilegiar-se uma regra mnemônica no estudo dos modos verbais, mais especificamente do imperativo (CASTILHO, 2014, p.439). 
Essa forma de abordagem da noção de ordem e do Modo Imperativo, nas Gramáticas de Língua Portuguesa, permite que se identifique a existência de movimento a favor de uma nova visão e tratamento dessa questão. Essa mudança, no entanto, precisa produzir frutos em forma de resultados produtivos nas salas de aula, principalmente naquelas com foco em PLE.

\subsection{Manuais de português para estrangeiros}

Nos livros de Português para estrangeiros, foram encontradas situações diversas: da ausência do tratamento do Modo Imperativo a uma abordagem, de certa forma, tradicional. A limitação à apreensão da teoria e à realização de exercícios de fixação foi a tônica dos exercícios analisados. A ordem de apresentação dos autores parte da ausência do tratamento do tema àquele que o faz de forma explícita, nesta ordem: Grannier e Henriques (2001), Lombello e Baleeiro (1983) e Lima (1999).

A dupla Grannier e Henriques (2001), cuja obra é apresentada em dois volumes (I e II), esclarece que a produção é direcionada aos estágios iniciante e intermediário no aprendizado da Língua. Os dois livros apresentam muitos textos não verbais e exercícios em torno de situações do cotidiano, em contextos de interação. Ambos os exemplares não fazem referência alguma ao Modo Imperativo nem à 
noção de ordem. Vale ressaltar também que não se percebe nenhuma referência a qualquer nomenclatura gramatical nesses volumes.

Já o segundo livro analisado ${ }^{3}$ destina um capítulo ao estudo do Modo Imperativo, no entanto, apresenta o mesmo padrão das Gramáticas tradicionais de Língua Portuguesa. Esse tópico é restrito a duas páginas, com enfoque apenas na $3^{a}$ pessoa do discurso (singular e plural). Foi identificada, em alguns exercícios, a presença de verbos modais que poderiam ter sido explorados; contudo, não houve nenhum tipo de abordagem nesse sentido. A seguir, um exemplo de exercícios no qual foi mantido o modelo tradicional, cujo foco está na forma verbal do Imperativo e sua reprodução.

C. Substituir:

1. Não percam o livro!

Espero que vocês não percam o livro.
a) Trocar
b) Destruir
(...) (LOMBELLO e BALEEIRO, 1983, p.172)

No exercício transcrito esperava-se que o aluno substituísse a forma verbal sublinhada pelas sugestões das alternativas - de A a F, partindo dos exemplos dados.

№1: "Não percam o livro!" / "Espero que vocês não percam o livro".

3 Lombello e Baleeiro, 1983. 
№2: "Compre o vinho!" / "João pede que você compre logo o vinho".

№3: "Não façam isto!" / "Ordeno que vocês não façam isto".

Observa-se que objetivo dessa atividade restringe-se ao exercício da conjugação correta do Modo Imperativo. Os exemplos da referida obra poderiam ter sido mais bem explorados a partir das seguintes observações: o primeiro exemplo de cada par de períodos, tem uma estrutura com período simples, cuja noção de ordem é direta. Já o segundo período de cada par é estruturado com período composto. Essa alteração na estrutura do período deixa clara a necessidade do acréscimo de um verbo modal na oração principal, cujo uso faz toda a diferença para a comunicação da noção de ordem, dentro de contextos específicos. Esse aspecto faz referência à ideia de atenuação e reforço, tematizado por Casteleiro, na obra a que se fez referência na introdução deste estudo.

A obra de Lima \& lunes (1999, p.74) segue também a abordagem tradicional do tema. Dedica um capítulo ao Modo Imperativo, com tratamento centrado na estrutura e em exercícios de fixação. A organização do livro gira em torno de situações comunicativas do cotidiano pelas quais, possivelmente, o estrangeiro pode passar. 
Apesar de fazer proposta de exercício de cunho semântico, o livro não aprofunda o tema; apenas conduz o aluno na execução de exercícios de condicionamento, com base nas diversas formas de fazer-se um pedido ou dar uma ordem. De modo geral, as atividades propostas seguem o mesmo modelo: a partir de perífrases, o aluno deve elaborar frases que mantenham a mesma mensagem daquelas sugeridas. Algumas dessas propostas compõem seções denominadas "Diga de outra forma".

Além do capítulo dedicado ao ensino da estrutura do Modo Imperativo, há outro, denominado "ordens e pedidos". Neste, é apresentado um modelo a partir do qual o aluno deve fazer igual, nas frases seguintes. Exemplificando: “Ajude-me! / Você pode me ajudar, por favor? / Será que você poderia me ajudar, por favor?" (LIMA \& IUNES, 1999, p.187).

A partir de algumas ilustrações, o livro propõe ao aluno que elabore uma ordem e depois a transforme em pedido. Vale ressaltar, no entanto, que algumas imagens não dão suporte visual adequado à ideia de pedido. 

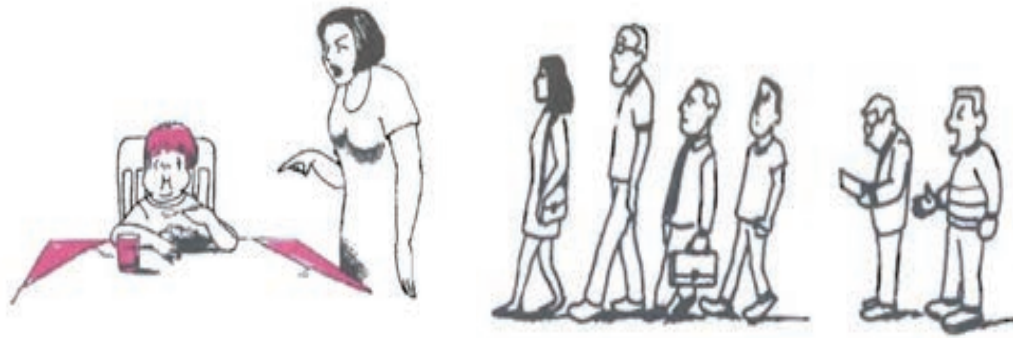

Figura 1 - LIMA \& IUNES, 1999, p.188 / Figura 2 - LIMA \& IUNES, 1999, p.188

Nas duas imagens, a personagem, supostamente, estaria dando uma ordem ou fazendo um pedido. A figura apresenta sinais que denotam apenas a noção de ordem: dedo apontando em sinal de ordem (imagem 1), boca aberta como se estivesse falando alto e sobrancelhas demonstrando irritação (imagens 1 e 2).

Esses dois exemplos mostram que o ensino do Modo Imperativo não pode ser restrito a exercícios mecânicos de substituição ou acréscimo de vocábulos, ou ao uso de pontuação. Devem, no entanto, explorar imagens e conceitos semióticos na abordagem do tema.

\section{UM POUCO DE TEORIA}

Seguindo uma linha de abordagem funcional, Casteleiro (2014, p.21) identifica que, não apenas o Modo Imperativo, mas o Indicativo, o Conjuntivo ${ }^{4}$ e o Condicional $^{5}$ fazem transmitir a noção de ordem, antes somente atribuída ao primeiro.

\footnotetext{
4 Atual modo subjuntivo

5 Refere-se a fatos que dependem de certa condição (ex.: Cantaria. cf. Bechara (2009, p.222).
} 
Dentro da espécie verbal, notamos que a "ordem" se exprime não apenas pelo Modo Imperativo, mas também pelos modos conjuntivo e indicativo e ainda pelo condicional, que neste caso tem valor modal. (CASTELEIRO, 2014, p.24)

A noção de ordem pode, muitas vezes, ser confundida com outras manifestações da vontade - como a exortação, a advertência e o conselho. Esse fato ocorre por fazerem uso das mesmas formas linguísticas. Somam-se ainda outras manifestações: o pedido, o desejo e a súplica. Por isso, o contexto e a situação de fala são indispensáveis na análise de muitos dos trechos selecionados. Alguns casos poderiam gerar dúvida, quanto ao caráter de ordem que emanam se apresentados isoladamente. Por isso, há necessidade da utilização de exemplos contextualizados.

Segundo Casteleiro, a noção de ordem pode ser comunicada por meio de formas verbais: diretas ou indiretas e formas não verbais: nominais, adverbiais ou interjetivas. Existe ainda a possibilidade de atenuação ou de reforço da noção de ordem, aspecto também analisado pelo autor (2014, p.201). No respectivo capítulo, percebe-se a contribuição dos aspectos culturais ressaltando a necessidade, ou não, dessa compensação na noção de ordem. 


\subsection{Atenuação e reforço na noção de "ordem"}

Os fatos culturais, muitas vezes subjetivos, demandam certa habilidade do falante no ato de comunicação. Por isso, a necessidade de atenuação ou reforço da ordem são fatores, muitas vezes, necessários na interação. Para Casteleiro,

a 'ordem', como manifestação da vontade, contém sempre alguma coisa de subjetivo; através dela, o ordenante comunica sempre algo de si mesmo; ainda que indiretamente, revela-nos a sua maneira de ser, a sua educação, a sua personalidade, a sua psicologia, em suma." (CASTELEIRO, 2014, p.201)

Nesse "algo de si mesmo" podem ser incluídos também elementos da cultura que caracterizam o falante nativo da língua. Por não serem excludentes, as noções de atenuação e reforço podem, de acordo com as circunstâncias, conferir graus maiores ou menores de reforço ou de atenuação à noção de ordem. Segundo o autor:

Embora haja muitas expressões em que atenuação e reforço se opõem, noutras porém tal distinção não é nítida e depende do ponto de vista sob o qual as encaramos. (...) Parece, portanto, que atenuação e reforço não são elementos opostos. Em muitos casos o que observamos é um grau maior ou menor de atenuação." (CASTELEIRO, 2014, p.204-205) 
Muitas são as possibilidades de se transmitir uma ordem. Essa diversidade decorre de fatores de natureza diversa que incidem no momento de interação influenciando, moldando a fala e acrescentando-Ihe sentido. Esses fatores, muitas vezes negligenciados no ensino da Língua, fundamentam e justificam a necessidade de atenuação ou de reforço da ordem. Em função disso, o ensino da Língua necessita de abordagem para além da nomenclatura e das normas gramaticais.

\section{A NOÇÃO DE ORDEM E A SEMIÓTICA}

Neste tópico analisaremos os meios de valorização explícita, por meio da antífrase como forma de reforçar uma ordem. De acordo com o dicionário de linguística: “Dá-se o nome de antífrase ao emprego de uma palavra ou de um grupo de palavras com sentido contrário à sua verdadeira significação, por preocupação estilística, ironia ou respeito a um tabu" (DUBOIS et al, 2006). A despeito das possibilidades apresentadas por Casteleiro (CASTELEIRO, 2014), justifica-se essa escolha por se tratar de um processo a partir do qual o ordenante induz o executante a fazer o contrário da ordem dada. Fato que pode induzir o aprendiz de PLE ao erro. Nesse caso, o saber linguístico não se limita à simples decifração do código escrito, mas abarca uma série de conhecimentos do âmbito cultural. 
Dessa forma, dois pontos devem ser considerados: Primeiro, o transtorno possível de ser causado para o aprendizado da Língua, visto que o aprendiz iniciante apreende o sentido de modo bastante literal. O segundo ponto decorre da construção da antífrase que associa elementos suprassegmentais e não verbais à linguagem verbal de modo aparentemente contraditório. Por isso, entende-se pertinente a adoção da Ciência Semiótica como aporte teórico para análise de situações de comunicação dessa envergadura.

Pode-se encontrar na Semiótica o suporte necessário para a construção do sentido em contextos com riqueza sígnica, cujos elementos se associam de forma aparentemente contraditória. Apresentam-se a seguir alguns dos fundamentos dessa Ciência para melhor direcionar a abordagem.

\subsection{Contribuição da semiótica}

Para desvendar os meios não explícitos na linguagem, que cooperam no processo de significação da mensagem, recorre-se aos fundamentos da Semiótica na análise desse tópico. De modo geral, define-se Semiótica como a Ciência dos signos. Entende-se por signo, genericamente falando, aquilo que substitui, indica ou representa algo. Aquilo que é usado em lugar de outro. Segundo Santaella, 
a Semiótica é a ciência que tem por objeto de investigação todas as linguagens possíveis, ou seja, tem por objetivo o exame dos modos de constituição de todo e qualquer fenômeno como fenômeno de produção de significação e de sentido. (2012, p.19)

Um signo pode manifestar-se de três modos: por meio de um ícone, de um índice ou de um símbolo. Segundo a pesquisadora, com base na teoria desenvolvida por Charles Sanders Peirce, a Semiótica engloba

categorias fundamentais, encontradas no pensamento e descobertas pela análise reflexiva dos fenômenos, estão também presentes na natureza básica das coisas, sejam elas físicas ou psicológicas. (...) Como tal, são conceitos simples aplicáveis a qualquer objeto. (SANTAELLA, 2012, p.59)

Quando o signo mantém semelhança com o objeto que representa, ddemonstrando suas qualidades e imitando-o, é chamado de ícone. Já o índice, não substitui o objeto, aponta para ele. Mantém uma relação de contiguidade. Leva ao reconhecimento do objeto que representa. Por outro lado, o Símbolo representa uma convenção. É resultado de uma combinação, de uma lei.

Contudo, o enfoque aqui sugerido apresenta exemplos de atividades linguísticas, nas quais a noção de ordem é abordada a partir da antífrase. Ou seja, o signo deflagrado 
pela forma verbal aponta, necessariamente, para uma significação contrária. Desse modo, o entendimento da mensagem somente será levado a bom termo quando analisada dentro do contexto no qual se insere.

\section{A NOÇÃO DE ORDEM E O ENSINO}

Inicialmente, importa apresentar os critérios seguidos por Casteleiro na produção de sua obra, cujos exemplos servem a presente proposta. A seleção e a delimitação do córpus são calcadas em trechos, cuja noção de ordem contempla a Língua Portuguesa do século XX. A dificuldade na recolha de material linguístico, que demandaria "surpreender conversas espontâneas" (CASTELEIRO, 2014, p.29), condiciona o autor a concentrar esforços num córpus "constituído por 51 obras portuguesas e 24 brasileiras, umas e outras selecionadas nos domínios do romance, da novela e do teatro" (p.12-13); cuja publicação data entre os anos de 1900 e 1960 (p.29).

Segundo o autor, a escolha dos gêneros referidos é justificada pelo fato de "parecerem refletir melhor o caráter ativo da língua falada, embora sob certos limites" (CASTELEIRO, 2014, p.29). Em função do córpus selecionado pelo autor, os meios de valorização implícita, foco de análise desta proposta, aparecem no texto por intermédio do narrador. 
Como o próprio nome indica, os meios de valorização implícita: entoação, gestos e mímicas, são externos aos fatos linguísticos. Por tratar-se de meios não explícitos na linguagem verbal, recorre-se aos fundamentos da Semiótica, com base nas pesquisas desenvolvidas por Santaella (2012). Nesse sentido, as propostas aqui apresentadas partem da associação de imagens aos exemplos elencados da obra de Casteleiro (2014), com o recurso da antífrase.

Segundo Casteleiro, os exemplos calcados na antífrase apresentam um dos seguintes aspectos: o desafio, a ironia ou a advertência. O recurso mais usual é o desafio, que se aproxima bastante da ameaça.

Este processo antifrástico (...) consiste no seguinte: sob ameaça mais ou menos velada, o ordenante desafia o executante a fazer aquilo que vai contra a vontade de $A$. O objetivo do ordenante é precisamente levar o executante a abster-se de praticar aquilo que o contraria. (CASTELEIRO, 2014, p.234)

O segundo aspecto é a ironia, observada num contexto em que o ordenante usa a antífrase para incitar "o executante a praticar um ato cujas consequências funestas ele será o primeiro a suportar" (CASTELEIRO, 2014, p.236). O terceiro aspecto levantado por Casteleiro aproxima-se da advertência. Segundo o autor, não há uma ameaça explícita, 
mas o ordenante adverte quanto a determinado tipo de ação para que não haja reclamações posteriores. Dentro desse contexto, foram selecionados alguns exemplos apresentados por Casteleiro, a partir dos quais foram feitas análises e propostas de abordagem.

\subsection{A noção de ordem em exemplos de antífrase}

Analise-se o seguinte exemplo: "A, ao criado: '- Continua a fazer-se de besta comigo que te dou um bofetão"” (CASTELEIRO, 2014, p.235). O desafio é claro. A ameaça explícita da segunda parte da fala "te dou um bofetão", por si só, seria suficiente para que se percebesse a seriedade ou urgência no cumprimento da ordem dada. No entanto, qual a necessidade da ameaça? Quais são os elementos do contexto para que o ordenante use esse recurso? De acordo com Casteleiro,

geralmente, o ordenante emprega a forma da segunda pessoa do singular do imperativo (correspondente ao tratamento de 'tu'), quando o executante é um igual ou um inferior, com os quais mantém relações de parentesco ou de familiaridade; indica, por conseguinte, uma certa intimidade e dá à 'ordem' um matiz afetivo. (2014, p.112)

Nota-se então que, havia certa proximidade entre os interactantes. Provavelmente, essa intimidade produziu, no executante, resistência em obedecer. Associe-se a isso 
a hierarquia social. Trata-se de um superior e um criado. A informação dessa hierarquia na fala do narrador é índice de autoridade, pressupõe-se que nessa relação o criado conhece a necessidade de sua obediência. Outro ponto interessante é a ordem dada "Continua a fazer-se de besta comigo". A expressão "fazer-se de besta" carrega vários sentidos "fingirse de bobo", "fingir-se de desentendido", sempre com vistas a aproveitar-se de uma situação.

Considerando que, na verdade, não é da vontade do ordenante que o executante continue a fingir-se de bobo, por isso faz a ameaça ao final; o leitor é levado a concluir que a expressão "Continua a fazer-se de besta", no contexto apresentado, funcionaria como um signo desorientador, uma vez que essa ordem não era para ser obedecida. Acrescentese à parte verbal analisada, dados extralinguísticos como a entonação e a fisionomia do ordenante, num contexto real de interação. Teremos outros signos que funcionarão como ferramentas ao entendimento da antífrase.

No segundo exemplo, classificado pelo autor como ironia, "Um polícia, a um rapaz que se pendurou num elétrico: 'Faça muitas dessas!'” (CASTELEIRO, 2014, p.236), repete-se a hierarquia social já analisada. Trata-se de uma autoridade policial e um jovem. A contextualização contribui para o 
entendimento da fala irônica do policial em relação ao ato cometido pelo rapaz, de "pendurar-se num elétrico", atitude certamente proibida. Associando esses dois signos: atitude proibida e presença de uma autoridade policial, tem-se por natural uma ação coerciva para sanar o problema. No entanto, um signo desorientador surge representado na ordem do policial: “- Faça muitas dessas!”, em vez de "saia já daí" ou "desça daí".

É importante observar que nesse exemplo não houve necessidade de ameaça ou desafio, pois as consequências são inerentes ao campo de ação de uma autoridade policial. Convém reiterar também a importância da entonação e da fisionomia na construção do significado.

Por fim, um último exemplo de antífrase: “O capataz, a uma assalariada: '- Oh, cachopa! ... Mete-te com os rapazes e depois diz que o toicinho tem bicho.'"' (CASTELEIRO, 2014, p.237). Mais uma vez, como nos dois exemplos anteriores, os níveis de hierarquia estão presentes no contexto. Nesse período não há ameaças, como no primeiro modelo analisado; entretanto, o tom de advertência é semelhante. A mesma forma pode ser verificada no uso da segunda pessoa do singular no tratamento, o que denota proximidade entre os participantes. 
Já a expressão "o toicinho tem bicho", parece apresentar sentido similar a "tem caroço nesse angu", conotando algo desagradável, indigesto, de difícil aceitação. Percebe-se que, nesse contexto, essa afirmação apresenta tom de advertência. Nesse trecho, a carga semântica recai principalmente no verbo, "meter-se". Funcionando como signo desorientador. Ou seja, a ordem "mete-te" não é para ser obedecida. Na verdade, não é bom que a moça se envolva com os rapazes.

\subsection{Algumas sugestões de abordagem}

Calcadas nas considerações levantadas, propõemse duas linhas de ação para o ensino da noção de ordem. Primeiramente, usando os exemplos acima analisados, propõe-se a associação de algumas imagens, cujas fisionomias são possíveis nos contextos apresentados. O professor pode selecionar as imagens e propor a análise em sala, ou sugerir que os próprios alunos selecionem as imagens que melhor representem as mensagens analisadas.

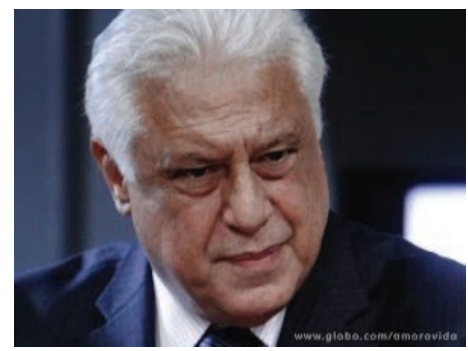

Imagem 1 
Correspondente ao aspecto do desafio, proposto por Casteleiro, a imagem 1 poderia, sem muito esforço, enquadrarse no contexto da fala: "Faça muitas dessas!" (CASTELEIRO, 2014, p.236). Os sinais de desaprovação que, provavelmente, acompanhariam o enunciado estão presentes na imagem. As sobrancelhas franzidas e a boca cerrada, compondo a gravidade da expressão facial, respaldam a mensagem da ameaça velada representada no contexto. São dados extralinguísticos que confrontam o signo desorientador: a expressão enunciada. Dentro desse contexto, a mensagem da antífrase a ser interpretada é "saia já daí" ou "desça daí".

A Imagem 2, a seguir, pode configurar reação a uma postura não esperada em uma interlocução. A fisionomia da personagem apresenta sinais que podem ser interpretados dentro de um contexto de ordem. A sobrancelha esquerda levantada e os olhos arregalados são apropriados a uma situação em que alguém de um nível hierárquico inferior afronta um seu superior.

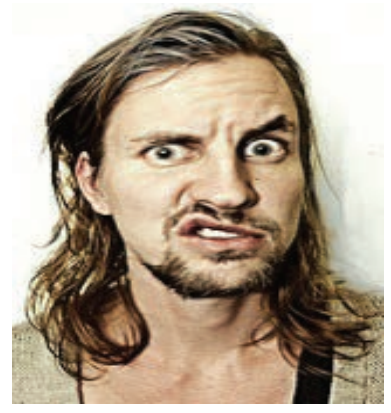

Imagem 2 
Essa fisionomia associada à expressão da boca aberta em sinal de ameaça completa os sinais necessários ao entendimento da primeira parte em destaque no fragmento: "Continua a fazer-te de besta comigo que te dou um bofetão" (CASTELEIRO, 2014, p.235), como uma ironia e não uma ordem a ser obedecida. Ou seja, não é desejo de quem ordena que seu interactante continue a "fazer-se de besta". Nesse contexto, a interpretação da antífrase é reforçada pela ameaça que segue direcionada ao entendimento da ordem "Não se faça de besta comigo".

As imagens 3 e 4, a seguir, apresentam diferença significativa em relação às anteriores.
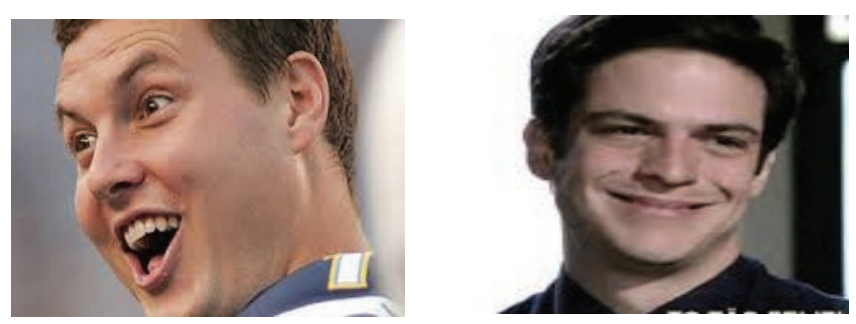

Imagem 3 / Imagem 4

O conjunto de sobrancelhas levantadas, olhos arregalados e boca aberta (Imagem 3) - esboçando um sorriso - sinalizam mais um sinal de deboche que de irritação. Tanto os olhos quanto a boca mostram um leve sorriso que não é de alegria. Associada à fala: "Mete-te com os rapazes e depois diz que o toicinho tem bicho'" (CASTELEIRO, 2014, p.236), a expressão 
poderia ser uma mistura de surpresa com o comportamento da moça (cachopa) e de uma advertência para não "meter-se com os rapazes".

Já a Imagem 4, apesar de bastante diferente da anterior, também poderia ser usada nesse mesmo contexto, devido ao "sorriso amarelo" do personagem que indica desagrado com a situação. Ambas as imagens não são associadas ao tom de ameaça, mas corroboram a advertência expressa pela mensagem verbal.

A segunda linha de ação aqui proposta consiste em introduzir a dramatização como recurso pedagógico no ambiente de aprendizado. Com esse enfoque, os Parâmetros Curriculares Nacionais sugere, como recurso pedagógico no âmbito da variação linguística, a "análise da força expressiva da linguagem popular na comunicação cotidiana, na mídia e nas artes, analisando depoimentos, filmes, peças de teatro, novelas televisivas, música popular, romances e poemas" (BRASIL, 1998, p.82).

Levando o aluno a interpretar a cena proposta, orientado por fatores extralinguísticos: gestos, entonações, mímicas etc., a possibilidade de apreensão da mensagem aumenta consideravelmente. Principalmente, quando essa mensagem apresenta subjetividades como aquelas que foram analisadas nesta pesquisa. 


\section{CONCLUSÃO}

A partir das análises feitas, percebe-se a necessidade de serem incluídas estratégias que possibilitem a representação de atos de comunicação diversos. Os recursos devem apresentar contextos nos quais o uso e a observação da linguagem não verbal sejam significativas, tais como: representação teatral, projeção de filmes, leitura de imagens e outras formas que levem o aluno a experimentar a diversidade de signos facilitadores do processo de significação.

Alguns dos gramáticos analisados trabalham com uma abordagem diferenciada para o estudo dos modos verbais, inclusive do Imperativo. No entanto, ainda existem lacunas para preencher tanto pelas Gramáticas de Língua Portuguesa de um modo geral, quanto pelos manuais específicos para o ensino de PLE.

Uma dessas lacunas faz referência a aspectos culturais. Por isso, muitos estudiosos da área de Língua Portuguesa como língua estrangeira têm se pronunciado a esse respeito. Segundo Meyer, "Só a partir de abordagem interculturalista - sem abandonar o foco na forma, claro - se poderá contribuir de forma efetiva para um ensino eficaz de PL2E" (MEYER, 2013, p.13).

Em função do exposto, constata-se que não se pode desenvolver o ensino da língua com base, unicamente, na correção gramatical, mas com a desejável adequação ao 
contexto no qual se insere. Portanto é inegável a necessidade da intercessão com a cultura no ensino de qualquer língua, principalmente no âmbito de PLE.

\section{REFERÊNCIAS}

BECHARA, Evanildo (2009). Moderna Gramática Portuguesa. 37ạ edição. BRASIL, Secretaria de Educação Fundamental (1998). Parâmetros curriculares nacionais: terceiro e quarto ciclos do ensino fundamental: língua portuguesa/ Secretaria de Educação Fundamental. Brasília: MEC/ SEF, p.106.

CASTELEIRO, João Malaca (2014). A arte de mandar em Português: estudo sintático-estilístico baseado em autores portugueses e brasileiros. Rio de Janeiro: Lexikon.

CASTILHO, Ataliba T. de. (2012). Nova Gramática do Português Brasileiro. São Paulo: Contexto.

CEGALLA, Domingos Paschoal (2008). Novíssima Gramática da Língua Portuguesa. São Paulo, Companhia Editora Nacional.

CUNHA, Celso; CINTRA, Lindley. (2008). Nova Gramática do português contemporâneo. 5a ed. Rio de Janeiro: Lexikon.

DUBOIS, Jean et al (2006). Dicionário de linguística. Izidoro Blikstein (Org.). São Paulo: Cultrix.

GRANNIER, Daniele M.; HENRIQUES, Eunice R. (2001) Interagindo em Português. Textos e Visões do Brasil. Vols. I, II. Brasília: Thesaurus.

LIMA, Emma Eberlein; IUNES, Samira (1999). Falar ... Ler ... Escrever... Português. Um curso para estrangeiros. 2a Edição, 5a reimp. Editora Pedagógica e Universitária LTDA. SÃO PAULO: EPU.

LIMA, Rocha. (2013) Gramática normativa da língua portuguesa. Rio de Janeiro: Editora José Olympio.

LOMBELLO, Leonor; BALEEIRO, Marisa. (1983). Português para falantes de Espanhol (Edição Experimental). Departamento de Linguística Aplicada Instituto de Estudos da Linguagem. São Paulo: UNICAMP/ FUNCAMP/MEC. 
MEYER, Rosa Marina de Brito. (2013). Para o bem ou para o mal: a construção de identidade pelo falante de PL2E a partir de estereótipos de brasilidade - uma questão intercultural. In MEYER, R. M. de B e ALBUQUERQUE, A. (Orgs). Português para Estrangeiros: questões Interculturais. Rio de Janeiro: Ed. PUC-Rio.

SANTAELLA, Lúcia (2012). O que é Semiótica. São Paulo: Brasiliense.

\section{ANEXOS}

Imagem 1 - http://gshow.globo.com/novelas/amor-a-vida/Vem-por-ai/noticia/2013/07/ babou-cesar-investiga-nascimento-de-paulinha-e-coloca-glauce-contra-a-parede.html - acesso em 24.Abr.2015

Imagem 2 - http://forum.priston.com.br - acesso em 28.Jul.2015

Imagem 3 - $h$ ttp://forum.priston.com.br/printthread.php?tid=85361\&page=2 - acesso em 28.Jul.2015

Imagem 4 - http://www.noveludo.com.br - acesso em 28.Jul.2015

Márcia da Gama Silva Felipe é Doutoranda em Língua Portuguesa (UERJ), Mestre em Língua Portuguesa (UERJ / 2017). Especialização em Língua Portuguesa (Liceu Literário Português / 2006). Graduação e Licenciatura em Letras - Língua Portuguesa/Literaturas (UERJ / 2002). Professora concursada - Secretaria Estadual de Educação do Governo do Estado do Rio de Janeiro e Secretaria Municipal de Educação do Rio de Janeiro. Atua nas disciplinas de Língua Portuguesa, Literatura e Redação. Membro do grupo de pesquisa Semiótica, Leitura e Produção de textos (SELEPROT), da Asociación de Linguística y Filología de América Latina (ALFAL) e da Associação Internacional de Linguística do Português (AILP). 